DOI: 10.20472/IAC.2019.046.015

\title{
GOUTAM POHIT
}

Jadavpur University, India

\section{VIBRATION CONTROL OF A CAR SUSPENSION SYSTEM USING A MAGNETORHEOLOGICAL DAMPER WITH FUZZY LOGIC CONTROLLER}

\begin{abstract}
:
The automotive suspension system connects a vehicle's wheels to its body while bearing the weight of the vehicle. The primary task of the suspension system is to provide a balance between ride handling and ride quality, which are at constant odds with one other. They have to be modelled and tuned to find the perfect compromise. Most vehicles today use the traditional passive suspension system. The major disadvantage of these systems is that they do not provide good ride characteristics. On the other hand, some luxury cars use the active suspension system. The constraint with these systems is that they rely too heavily on the ECU of the vehicle and are expensive. Semi-active suspension systems combine the positive aspects of the passive and active suspension systems to bring about better dynamic characteristics of the vehicle. Magnetorheological (MR) dampers are innovative devices used in semi-active suspension systems. The MR fluid present within the damper provides appropriate damping depending on the condition of the road. The behaviour of the MR damper is predicted using the Bouc-Wen hysteresis mathematical model. Designing the control strategy is the most critical part of the semi-active suspension system. Fuzzy Logic control is utilized to enhance the performance of the semi-active suspension system. The dynamic model of the semi-active suspension system is developed using the concepts of vehicle dynamics. The dynamic model was created in the Simulink environment of MATLAB.

The simulation of the dynamic vehicle models was conducted on different road profiles. The fuzzy logic control, which was implemented here, has shown the best response in terms of stability as well as effectiveness. This type of control allows for superior dynamic characteristics resulting in a more pleasant ride. This type of control strategy will pave the way for intelligent automotive suspension systems in the future.
\end{abstract}

\section{Keywords:}

Magnetorheological damper, automotive suspension, semi-active suspension system, fuzzy logic control, 